INTERNATIONAL JOURNAL OF RESEARCHES IN BIOSCIENCES, AGRICULTURE \& TECHNOLOGY (C) VISHWASHANTI MULTIPURPOSE SOCIETY (Global Peace Multipurpose Society) R. No.MH-659/13(N) www.vmsindia.org

\title{
OPTICAL INVESTIGATIONS ON EUZNNABIB GLASSES
}

\author{
${ }^{1}$ Hegde V., ${ }^{1}$ Hegde H., ${ }^{2}$ Dwaraka V.C.S., ${ }^{3}$ Mahato K.K and ${ }^{3 K a m a t h ~ S . D . ~}$ \\ ${ }^{1}$ Manipal Institute of Technology, Manipal University (Manipal) India \\ ${ }^{2}$ Sri Venkateswara University, Tirupati (A.P) India \\ ${ }^{3}$ School of Life Sciences, Manipal University (Manipal) India \\ Email: sudhakamath6@gmail.com
}

\begin{abstract}
A new family of novel optical glasses $10 Z n O-5 \mathrm{Na}_{2} \mathrm{CO}_{3}-10 \mathrm{Bi}_{2} \mathrm{O}_{3}-(75-\mathrm{x}) \mathrm{B}_{2} \mathrm{O}_{3}-\mathrm{xEu}_{2} \mathrm{O}_{3}(\mathrm{x}=0,0.1$, $0.5,1,1.5,2,3 \mathrm{~mol} \%)$, are synthesized by melt quench technique. Optical properties were investigated for their luminescence behavior through various spectroscopic techniques such as UV-Vis -NIR absorption, excitation, emission, decay profiles and color measurements at room temperature. Judd Ofelt intensity parameters $\left[\Omega_{2}, \Omega_{4}\right]$ estimated form PL spectra were used to predict the lasing properties of the glasses like total radiative life time, branching ratio, emission cross-section and optical gain. From the measured values of emission cross-sections, branching ratios, and strong photoluminescence features, $0.5 \mathrm{~mol} \%$ of $\mathrm{Eu}^{3+}$ ions doped $\mathrm{ZnNaBiB}$ glasses showed optimum performance and are potential novel optical luminescent material for red light generation at $613 \mathrm{~nm}$.
\end{abstract}

Keywords: Europium doped, Optical absorption, Photoluminescence

\section{Introduction:}

In recent years, glasses doped with RareEarth ions $\left(\mathrm{RE}^{3+}\right)$ have drawn much attention due to their potential applications in solid state lasers, optical amplifiers, three-dimensional displays, planar wave guides, field emission displays, white light emitting diodes, optoelectronic devices such as short wavelength (visible) lasers, and high density frequency domain optical data storage [1-8]. The radiative properties of these glasses depend on the concentration of the $\left(\mathrm{RE}^{3+}\right)$ ions as well as the chemical environment of the host material and the nature of neighbouring ion if more than one type of (rare earth) ion is present [7]. These glasses have proved to be luminescence materials as they have high emission efficiencies. These emissions correspond to $4 f-4 f$ and $4 f-5 d$ electronic transitions in the $\mathrm{RE}^{\mathrm{n}+}$ [6]. The 4f-4f transition gives an especially sharp fluorescence pattern from the UV-VIS to the infrared region (NIR) [4,6]. This is due to shielding effects of the outer $5 \mathrm{~s}$ and $5 \mathrm{p}$ orbitals on the $4 \mathrm{f}$ electrons [6]. Luminescent properties of these rare earth (which is decided by the chemical composition of the host) ions like emission cross section and radiative life time dependent on the phonon energy of the host glassy system [9]. Among the given rare earths, triply ionized europium ions has got technological importance due to the prominent red and orange emission peak around $600 \mathrm{~nm}$, used in various field emission displays as well as red light emitting diodes $[7,9,15,16]$. In the present paper, we have explored a new family of novel optical glasses based on $\mathrm{ZnO}-\mathrm{Na}_{2} \mathrm{CO}_{3}-$ $\mathrm{Bi}_{2} \mathrm{O}_{3}-\mathrm{B}_{2} \mathrm{O}_{3}-\mathrm{Eu}_{2} \mathrm{O}_{3}$ with different concentrations of europium.

\section{Experimental: \\ Sample Preparation:}

Europium doped multi-component $10 \mathrm{ZnO}-$ $5 \mathrm{Na}_{2} \mathrm{CO}_{3}-10 \mathrm{Bi}_{2} \mathrm{O}_{3}-(75-\mathrm{x}) \mathrm{B}_{2} \mathrm{O}_{3}-\mathrm{x}$ $\mathrm{Eu}_{2} \mathrm{O}_{3}(\mathrm{x}=0.1,0.5,1,1.5,2,3 \mathrm{~mol} \%)$ $\mathrm{ZnNaBiB}$ glasses have been prepared by melt quench technique. Required amount of host chemicals weighed and grounded thoroughly using an agate mortar and pestle. The fine powder thus formed was transferred to a porcelain crucible and melted at $950{ }^{\circ} \mathrm{C}$ for 2 hour in a temperature controlled electric furnace. After the retirement of the melting period, the molten mass was quenched on a preheated rectangular stainless steel mould. The raw glasses thus prepared were annealed at glass transition temperature for 3 hours to remove the thermal stresses induced in the glass matrix due to the rapid quenching process. Different grain size emery sheets were used to polish the glasses to get transparent bubble free europium doped glasses for further 
characterization. UV-Vis-NIR absorption spectra of the samples were recorded using Perkin Elmer Lambda $\quad-750$ spectrophotometer with $1 \mathrm{~nm}$ resolution, in the wavelength region 250 to $2500 \mathrm{~nm}$. Photoluminescence [excitation and emission spectra] and life time decay measurements were done using Edinnburg Spectro Fluorimeter-950 with xenon flash lamp and pulsed laser as excitation sources. Emission spectra of $\mathrm{ZnNaBiBEu}$ glasses were recorded in 520 to $750 \mathrm{~nm}$ spectral region and optical properties of the glasses monitored at 613 $\mathrm{nm}$.

\section{Results and Discussion}

\section{Optical Properties:}

\section{Absorption Spectroscopy}

Overlaid UV-Visible -NIR absorption spectra of $\mathrm{Eu}^{3+}$ doped $\mathrm{ZnNaBiB}$ glass is shown in figure 1 (a). Absorption bands in the figure 1 (a) were attributed to the $4 \mathrm{f}-4 \mathrm{f}$ intra band electronic transitions, takes place from ground state ${ }^{7} \mathrm{~F}_{0}$ andthermally populated first excited state ${ }^{7} \mathrm{~F}_{1}$ to next excited ${ }^{5} \mathrm{~L}_{6}$, ${ }^{5} \mathrm{D}_{2},{ }^{5} \mathrm{D}_{1}$ and ${ }^{7} \mathrm{~F}_{6}$ state $[7,9]$. Each absorption spectrum showed a maximum of 6 transitions attributed to ${ }^{7 \mathrm{~F}_{0}} \longrightarrow\left(\mathrm{L}_{6},{ }^{5 \mathrm{D}_{1}}\right.$, $\left.{ }^{5} \mathrm{D}_{2}\right),{ }^{7} \mathrm{~F}_{1} \longrightarrow{ }^{5} \mathrm{D}_{1}$ in UV-Vis region and two transitions $\left({ }^{7} \mathrm{~F}_{0} \longrightarrow{ }^{7} \mathrm{~F}_{6}\right.$ and $\left.{ }^{7 \mathrm{~F}_{1}} \longrightarrow{ }_{\left.7 \mathrm{~F}_{6}\right)}\right)$ in NIR region at wavelengths 394, 465, 526, 534, 2097, 2207nm respectively. Intensity of each absorption peak increased as $\mathrm{Eu}^{3+}$ concentration increased in the base of $\mathrm{ZnNaBiB}$ glass matrix. The plot between (ahu) and energy (hu) known as Tauc plot [7] used to calculate the band gap energy $\left[\mathrm{E}_{\mathrm{g}}\right]$ is shown in Fig 1 (b). The value of (hu) at the point where $(\mathrm{ahu})^{(1 / 2)}$ becomes zero yields a directmeasure of the optical band gap energy [7].

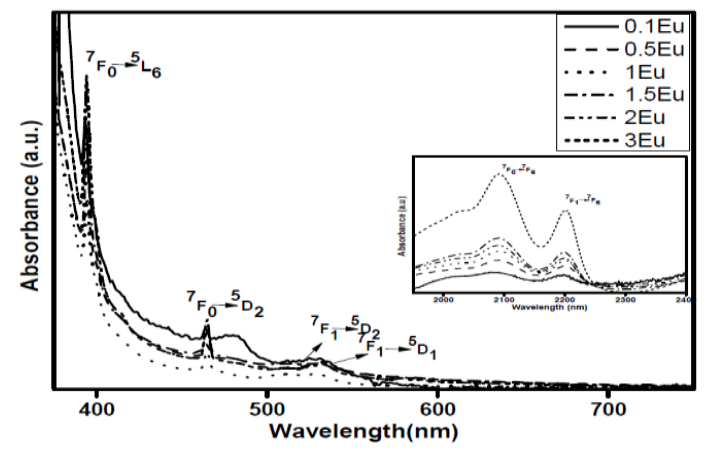

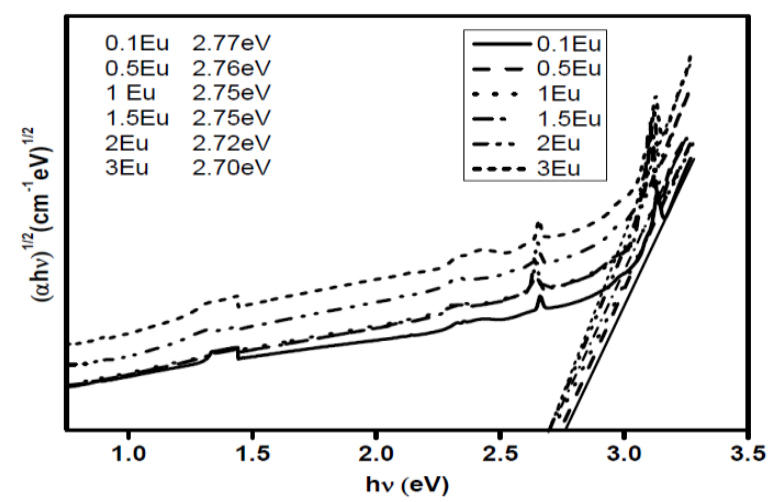

Fig.-1. (a) Overlaid absorbance spectra in UV-Vis-NIR region (b) Tauc's plot of $\mathrm{Eu}^{3+}$ doped $\mathrm{ZnNaBiB}$ glasses.

Overlaid Tauc's plot of $\mathrm{Eu}^{3+}$ doped $\mathrm{ZnNaBiB}$ glasses is shown in Figure 1b). Band energy gap $\left[\mathrm{E}_{\mathrm{g}}\right]$ values measured through Tauc's plot were found to be $2.65,2.66,2.64,2.69$, $2.69,2.69$ respectively correspond to 0.1 , $0.5,1.0,1.5,2.0,3.0 \mathrm{Eu}^{3+}$ doped $\mathrm{ZnNaBiB}$ glasses. These values once again confirmed the insulating nature of the glasses and are almost same for all $\mathrm{Eu}^{3} \mathrm{doped}$ glasses.

\section{Photoluminescence Spectroscopy}

Excitation spectra, Emission spectra, J-O analysis and Radiative parameters

The excitation spectra [PLE] of $\mathrm{Eu}^{3+}$ doped ZnNaBiB glasses monitoring emission at $613 \mathrm{~nm}$ are shown in a figure 2 (a). Each PL spectrum comprises five emission bands at 580, 590, 613, 646, $702 \mathrm{~nm}$ respectively correspond to the ${ }^{5} \mathrm{D}_{0}$ to ${ }^{7} \mathrm{~F}_{0},{ }^{7} \mathrm{~F}_{1},{ }^{7} \mathrm{~F}_{2},{ }^{7} \mathrm{~F}_{3},{ }^{7} \mathrm{~F}_{4}$ transitions. Intensity of emission band increased with increase in $\mathrm{Eu}^{3+}$ concentration up to $0.5 \mathrm{~mol} \%$ and intensity quenching was observed with further increase in europium content in the glass network.

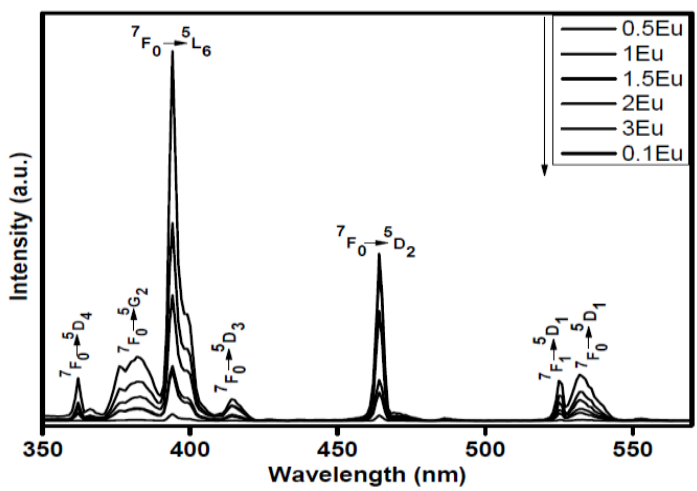




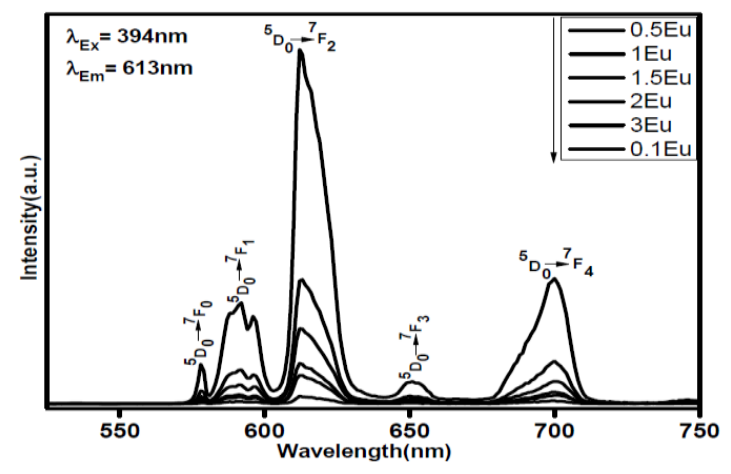

Fig.-2.(a) Overlaid (a) excitation and (b) emission spectra of $\mathrm{Eu}^{3+}$ doped $\mathrm{ZnNaBiB}$ glasses.

The decrease in peak intensity may be due to the self-quenching of excited $\mathrm{Eu}^{3+}$ ions when the concentration is more than the 0.5 mol \%. Judd-Ofelt [J-O] intensity parameters $[9,16]$ of $\mathrm{Eu}^{3+}$ doped $\mathrm{ZnNaBiB}$ glasses are obtained from the PL emission spectra. In $\mathrm{J}-\mathrm{O}$ analysis, electric induced dipole transitions $\left[{ }^{5} \mathrm{D}_{0}\right.$ to $\left.{ }^{7} \mathrm{~F}_{\mathrm{j}}(\mathrm{j}=2,4,6)\right]$ to host independent magnetic dipole transition [ ${ }^{5} \mathrm{D}_{0}$ to ${ }^{7} \mathrm{~F}_{1}$ ] will be used to estimate the $\mathrm{J}-\mathrm{O}$ intensity parameters $\Omega_{\lambda}(\lambda=2,4,6)[9,16]$.

Table-1. Judd-Ofelt parameters $\Omega_{\lambda}(\boldsymbol{\lambda}=2,4)$ (x 10-20) calculated from PL spectral and red to orange ratio $\left[\mathrm{R} / \mathrm{O}=\left({ }^{5} \mathrm{D}_{0} \rightarrow{ }^{7} \mathrm{~F}_{2}\right) /\left({ }^{5} \mathrm{D}_{0}\right.\right.$ $\rightarrow{ }^{7} \mathrm{~F}_{1}$ ) of $\mathrm{Eu}^{3+}$ ions in $\mathrm{ZnNaBiB}$ glasses.

\begin{tabular}{|l|l|l|l|}
\hline Glass Code & $\Omega_{2}$ & $\Omega_{4}$ & $\Omega_{6}$ \\
\hline Eu 0.1 & 4.12 & 3.28 & - \\
\hline Eu 0.5 & 4.23 & 3.32 & - \\
\hline Eu 1 & 4.01 & 3.53 & - \\
\hline Eu 1.5 & 3.87 & 3.32 & - \\
Eu 2.0 & 3.80 & 3.26 & - \\
Eu 3.0 & 3.71 & 3.22 & - \\
\hline
\end{tabular}

The calculated values of $\mathrm{J}-\mathrm{O}$ intensity parameters $\Omega_{2}, \Omega_{4}$, are presented in Table 1 . J-O parameters $\Omega_{2}>\Omega_{4}$ shown inTable 1 confirms the covalence nature of Eu-O in the glass. The essential radiative properties of the $\mathrm{Eu}^{3+}$ doped $\mathrm{ZnNaBiB}$ glasses were determined using $\mathrm{J}-\mathrm{O}$ intensity parameters. Radiative properties like, transition probability (A), total transition probability $\left(\mathrm{A}_{\mathrm{T}}\right)$, radiative life time $\left(\boldsymbol{\tau}_{\boldsymbol{R}}\right)$ and branching ratio $(\boldsymbol{\beta})$ will decide the lasing properties of prepared gasses [9-16]. Total radiative transition probability [Ат] estimated by adding the individual radiative transition probabilityA: $\quad \mathrm{A}_{\mathrm{T}}=\sum \mathrm{A}$

Lasing power of an emission transition is characterized by the branching ratio $(\beta)$ if its value is $>0.50$. Branching ratio $(\beta)$ which decides the potentiality of the lasing action of the lasing glass was calculated by: $\beta=\frac{\mathrm{A}}{\mathrm{A}_{\mathrm{T}}}$

Ability of the host in lasing emission determined by calculating the stimulated emission cross-section for ${ }^{5} \mathrm{D}_{0}$ excited state to lower state ${ }^{7} \mathrm{~F}_{1,2,4}$ given by: $\sigma_{\mathrm{se}}=$ $\frac{\lambda_{\mathrm{p}}^{4}}{8 \pi \mathrm{cn}^{2} \Delta \lambda_{\mathrm{p}}} \mathrm{A}$

Where $\lambda_{p}$ represents peak emission wavelength, $\Delta \lambda_{p}$ effective band width, $\sigma_{s e}$ peak stimulated emission cross-section, $\sigma_{s e} x \Delta \lambda_{p}$ gain bandwidth, c speed of light and $\mathrm{n}$ refractive index of the glass. The measured and calculated values of

$\lambda_{\mathrm{p}}, \Delta \lambda_{\mathrm{p}}, \sigma_{\mathrm{se}}, \sigma_{\mathrm{se}} \mathrm{x} \Delta \lambda_{\mathrm{p}}$ and $\beta$ for 0.5 europium doped glass are included All these values were found to be significantly high for the prominent transition ${ }^{5} \mathrm{D}_{0}-7 \mathrm{~F}_{2}$ and also for $0.5 \mathrm{~mol} \%$ $\mathrm{Eu}^{3+}$ doped $\mathrm{ZnNaBiB}$ glass [As our main focus is on developing good luminescent/lasing material, the optical/radiative parameters studied based on PL spectra are included only for 0.5 mol\% glass, as it showed optimal performance compared to other $\mathrm{Eu}^{3+}$ doped $\mathrm{ZnNaBiB}$ glasses explored in this study].

Table-2.Emission peak wavelength $\lambda_{\mathrm{p}}(\mathrm{nm})$, effective bandwidth $\left(\Delta \boldsymbol{\lambda}_{\mathrm{p}}\right)$, experimental branching ratios $\left(\beta_{\exp }\right)$, stimulated emission cross section $\left(\sigma_{\mathrm{se}} \times 10^{-22}\right)\left(\mathrm{cm}^{2}\right)$, gain band width $\left(\sigma_{\mathrm{se}} \times \Delta \boldsymbol{\lambda}_{\mathrm{p}}\right)\left(\mathrm{x} \quad 10^{-28}\right)\left(\mathrm{cm}^{3}\right)$ and optical gain $\left(\sigma_{\text {se }} \times \tau_{R}\right)\left(x_{10}^{-24}\right)(\mathrm{s})$ for the emission transitions of $\mathrm{ZnNaBiB} 0.5 \mathrm{Eu}$ glass.

\begin{tabular}{|l|l|l|l|l|l|l|}
\hline $\begin{array}{l}\text { Transition } \\
{ }^{5} \mathrm{D}_{0} \rightarrow\end{array}$ & $\boldsymbol{\lambda}_{\mathrm{p}}$ & $\Delta \boldsymbol{\lambda}_{\mathrm{p}}$ & $\beta$ & $\sigma_{\text {se }}$ & $\begin{array}{l}\sigma_{\text {se }} \mathrm{X} \\
\Delta \boldsymbol{\lambda}_{\mathrm{p}}\end{array}$ & $\begin{array}{l}\sigma_{\text {seX }} \\
{ }_{\mathrm{R}}\end{array}$ \\
\hline${ }^{7} \mathrm{~F}_{0}$ & 579 & 2.63 & 0 & 0 & 0 & 0 \\
\hline${ }^{7} \mathrm{~F}_{1}$ & 591 & 12.03 & 0.16 & 1.52 & 1.81 & 0.49 \\
\hline${ }^{7} \mathrm{~F}_{2}$ & 613 & 12.22 & $\mathbf{0 . 5 9}$ & 9.73 & 12.1 & 3.15 \\
\hline${ }^{7} \mathrm{~F}_{3}$ & 646 & 6.66 & 0 & 0 & 0 & 0 \\
\hline${ }^{7} \mathrm{~F}_{4}$ & 701 & 15.1 & 0.22 & 5.2 & 7.85 & 2.54 \\
\hline
\end{tabular}

Considering the values of all spectroscopic parameters $\left[\mathrm{A}, \sigma_{\mathrm{se}}, \sigma_{\mathrm{se}} \mathrm{x} \Delta \lambda_{\mathrm{p}}, \beta\right]$ studied on 
PL spectra, $0.5 \mathrm{~mol} \% \mathrm{Eu}^{3+}$ doped $\mathrm{ZnNaBiB}$ glass showed better performance. Hence, $0.5 \mathrm{Eu}^{3+}$ doped $\mathrm{ZnNaBiB}$ glass could be used as an active medium for lasing action and also suitable for high red light generating luminescent material at $613 \mathrm{~nm}$.

\section{Conclusion:}

We have developed a new family of novel optical glasses based on $\mathrm{ZnO}-\mathrm{Na}_{2} \mathrm{CO}_{3}-\mathrm{Bi}_{2} \mathrm{O}_{3}-$ $\mathrm{B}_{2} \mathrm{O}_{3}-\mathrm{Eu}_{2} \mathrm{O}_{3}$ using melt quench technique. Calculated values of radiative parameters using JO analysis like transition probability $\left(A_{T}\right)$, stimulated emission cross-section $\sigma_{\mathrm{se}}$, gain bandwidth $\left[\sigma_{\mathrm{se}} \mathrm{x} \Delta \lambda_{\mathrm{p}}\right]$,

branching ratio $[\beta]$ and quantum efficiency $[\eta]$ sho wed competitive results. Among various emission transitions, ${ }^{5} \mathrm{D}_{0}-{ }^{7} \mathrm{~F}_{2}$ transition possessed maximum J-O parameter $\left(\Omega_{2}\right)$ and stimulated emission cross-section ( $\left.\sigma_{\mathrm{se}}\right)$ indicating abundance of red color in present glasses. From the measured emission crosssections, branching ratios, life times, strong photoluminescence features, $0.5 \mathrm{~mol} \%$ doped $\mathrm{ZnNaBiB}$ glass showed optimum performance, are potential novel optical luminescent material for red light generation at $613 \mathrm{~nm}$.

\section{Acknowledgments:}

Authors are highly grateful to the Department of Science and Technology, Government of India, New Delhi (DST-SERB) for sanctioning the major project (Ref No: SB/S2/CMP-29/2013) and providing the financial assistance to carry out this work. The authors acknowledge Department of Physics, S.V. University, Tirupati, India for providing the experimental facility for photoluminescence study.

\section{References:}

A. Jha, B. Richards, G. Jose, T. TeddyFernandez, P. Joshi, X. Jiang, J. Lousteau, Rare-earth ion doped TeO 2 and $\mathrm{GeO} 2$ glasses as laser materials, Prog. Mater. Sci. $57 \quad$ (2012) 1426-1491. doi:10.1016/j.pmatsci.2012.04.003.

Vandana Sharma, S.P. Singh, G.S. Mudahar, K.S. Thind, Synthesis and Optical Characterization of Silver Doped Sodium Borate Glasses, New J. Glas.Ceram. 2 (2012) 133-137.

A. Ivankov, J. Seekamp, W. Bauhofer, Optical properties of Eu3+-doped zinc borate glasses, J. Lumin. 121 (2006) 123131. doi:10.1016/j.jlumin.2005.11.002.

Q. Jiao, J. Qiu, D. Zhou, X. Xu, Contribution of $\mathrm{Eu}$ ions on the precipitation of silver nanoparticles in Ag-Eu co-doped borate glasses, Mater. Res. Bull. 51 (2014) 315-319.

doi:10.1016/j.materresbull.2013.12.044.

S.A. Loureno, N.O. Dantas, E.O. Serqueira, w.E.F. Ayta, A.A. Andrade, M.C. Filadelpho, J.A. Sampaio, M.J. V Bell, M.A. Pereira-Da-Silva, Eu3+ photoluminescence enhancement due to thermal energy transfer in Eu2O3-doped $\mathrm{SiO} 2 \mathrm{~B} 2 \mathrm{O} 3 \mathrm{PbO} 2$ glasses system, J. Lumin. 131 (2011) 850-855. doi:10.1016/j.jlumin.2010.11.028.

P. Jeongmin, J.K. H., K. Sunghwan, C. JongKyu, K. J., L. P., I. S., X-ray and Proton Luminescences of Bismuth-borate Glasses, J. Korean Phys. Soc. 59 (2011) 657. doi:10.3938/jkps.59.657.

A. Wagh, Y. Raviprakash, V. Upadhyaya, S.D. Kamath, Composition dependent structural and optical properties of $\mathrm{PbF} 2-$ TeO2-B2O3-Eu2O3 glasses, Spectrochim. Acta Part A Mol. Biomol. Spectrosc. 151 (2015) 696-706. doi:10.1016/j.saa. 2015.07.016.

A.S. Aleksandrovsky, A.S. Krylov, A. V. Malakhovskii, A.M. Potseluyko, A.I. Zaitsev, A. V. Zamkov,Europium doped strontium borate glasses and their optical properties, J. Phys. Chem. Solids. 66 (2005) 75-79. doi:10.1016/j.jpcs.2004.05.009.

K. Swapna, S. Mahamuda, A.S. Rao, T. Sasikala, P. Packiyaraj, L.R. Moorthy, G.V. Prakash, Luminescence characterization of Eu3+ doped Zinc Alumino Bismuth Borate glasses for visible red emission applications, J. Lumin. 156 (2014) 80-86. doi: 10.1016/ j.jlumin. 2014.07.022.

M. Parandamaiah, K. Naveen Kumar1 and S. Venkatramana Reddy,Spectroscopic properties of $\mathrm{Eu}^{3+-}$ doped lithium sodium bismuth borate glasses for red luminescent opticaldevices,International Journal of Engineering And Science Vol.5, Issue 9 (2015), PP -16-22.

J. Kaewkhao, A. Pokaipisit, P. Limsuwan, Study on borate glass system containing with $\mathrm{Bi} 2 \mathrm{O} 3$ and $\mathrm{BaO}$ for gamma-rays 
shielding materials: Comparison with $\mathrm{PbO}$, J. Nucl. Mater. 399 (2010) 38-40. doi:10.1016/j.jnucmat.2009.12.020.

S. Bale, N.S. Rao, S. Rahman, Spectroscopic studies of Bi2O3-Li2O-ZnOB2O3 glasses, Solid State Sci. 10 (2008) 326-331. doi:10.1016/j.solidstatesciences. 2007.09.017.

H. Lin, W. Qin, J. Zhang, C. Wu, A study of the luminescence properties of Eu3+ -doped borate crystal and glass, Solid State Commun. $141 \quad$ (2007) 436-439. doi:10.1016/j.ssc.2006.12.003.

R.S. Kundu, S. Dhankhar, R. Punia, K. Nanda, N. Kishore, Bismuth modified physical, structural and optical properties of mid-IR transparent zinc boro-tellurite glasses, J. Alloys Compd. 587 (2014) 66-73. doi:10.1016/j.jallcom.2013.10.141.

K. Mariselvam, R.A. Kumar, Borate Glasses for Luminescence Applications Potential Materials for White LEDs and Laser Sources, 4 (2016) 55-64. doi:10.13189/ujc.2016.040202.

C.R. Kesavulu, K.K. Kumar, N. Vijaya, K.S. Lim, C.K. Jayasankar, Thermal, vibrational and optical properties of Eu3+doped lead fluorophosphate glasses for red laser applications, Mater. Chem. Phys. 141 (2013) 903-911. doi:10.1016/ j.matchemphys. 2013.06.021. 